\title{
Article \\ Family History and Gastric Cancer Risk: A Pooled Investigation in the Stomach Cancer Pooling (STOP) Project Consortium
}

\author{
Facundo Vitelli-Storelli ${ }^{1,+}\left(\mathbb{D}\right.$, María Rubín-García ${ }^{1,+}+{ }^{\infty}$, Claudio Pelucchi $^{2} \mathbb{D}$, Yolanda Benavente ${ }^{3,4, *}$,

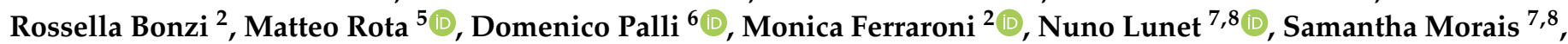 \\ Weimin Ye ${ }^{9}$, Amelie Plymoth ${ }^{9}$, Reza Malekzadeh ${ }^{10}{ }^{\circ}$, Shoichiro Tsugane ${ }^{11}{ }^{(0}$, Akihisa Hidaka ${ }^{11} \mathbb{D}$, \\ Nuria Aragonés 4,12 , Gemma Castaño-Vinyals ${ }^{4,13,14,15}{ }^{(0)}$, David Georgievich Zaridze ${ }^{16}$, Dmitry Maximovich ${ }^{16}$,

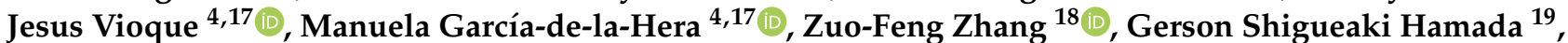 \\ Mohammadreza Pakseresht 10,20,21, Farhad Pourfarzi ${ }^{10,22}{ }^{(0)}$, Lina Mu ${ }^{23}$, Stefania Boccia ${ }^{24,25}{ }^{(0)}$, \\ Roberta Pastorino ${ }^{24}$, Guo-Pei Yu ${ }^{26}$, Areti Lagiou ${ }^{27}$ (D), Pagona Lagiou ${ }^{28,29}$, Eva Negri ${ }^{2}$, Carlo La Vecchia ${ }^{2}(\mathbb{D})$ \\ and Vicente Martín ${ }^{1,4}$ (i)
}

check for

updates

Citation: Vitelli-Storelli, F.; Rubín-García, M.; Pelucchi, C.; Benavente, Y.; Bonzi, R.; Rota, M.; Palli, D.; Ferraroni, M.; Lunet, N.; Morais, S.; et al. Family History and Gastric Cancer Risk: A Pooled Investigation in the Stomach Cancer Pooling (STOP) Project Consortium. Cancers 2021, 13, 3844. https:/ / doi.org/10.3390/cancers13153844

Academic Editor: Alain P. Gobert

Received: 21 June 2021

Accepted: 15 July 2021

Published: 30 July 2021

Publisher's Note: MDPI stays neutral with regard to jurisdictional claims in published maps and institutional affiliations.

Copyright: (C) 2021 by the authors Licensee MDPI, Basel, Switzerland This article is an open access article distributed under the terms and conditions of the Creative Commons Attribution (CC BY) license (https:// creativecommons.org/licenses/by/ $4.0 /)$
1 Grupo de Investigación en Interacciones Gen-Ambiente y Salud (GIIGAS), Institute of Biomedicine (IBIOMED), University of León, 24071 León, Spain; fvits@unileon.es (F.V.-S.); mrubig@unileon.es (M.R.-G.); vmars@unileon.es (V.M.)

2 Department of Clinical Sciences and Community Health, University of Milan, 20133 Milan, Italy; claudio.pelucchi@unimi.it (C.P.); rossella.bonzi@unimit.it (R.B.); monica.ferraroni@unimi.it (M.F.); eva.negri@unimi.it (E.N.); carlo.lavecchia@unimi.it (C.L.V.)

3 Cancer Epidemiology Research Programme, Catalan Institute of Oncology, IDIBELL, Hospitalet de Llobregat, 08908 Barcelona, Spain

4 Consortium for Biomedical Research in Epidemiology and Public Health (CIBERESP), 28029 Madrid, Spain; nuria.aragones@salud.madrid.org (N.A.); gemma.castano@isglobal.org (G.C.-V.); vioque@umh.es (J.V.); manoli@umh.es (M.G.-d.-1.-H.)

5 Department of Molecular and Translational Medicine, University of Brescia, 25121 Brescia, Italy; matteo.rota@unibs.it

6 Cancer Risk Factors and Life-Style Epidemiology Unit, Institute for Cancer Research, Prevention and Clinical Network, ISPRO, 08518 Florence, Italy; d.palli@ispro.toscana.it

7 EPIUnit-Instituto de Saúde Pública da Universidade do Porto, 4050-091 Porto, Portugal; nlunet@med.up.pt (N.L.); samantha.morais@ispup.up.pt (S.M.)

8 Departamento de Ciências da Saúde Pública e Forenses e Educação Médica, Faculdade de Medicina da Universidade do Porto, 4200-319 Porto, Portugal

9 Department of Medical Epidemiology and Biostatistics, Karolinska Institutet, 17177 Stockholm, Sweden; weimin.ye@ki.se (W.Y.); amelie.plymoth@ki.se (A.P.)

10 Digestive Oncology Research Center, Digestive Disease Research Institute, Tehran University of Medical Sciences, Tehran 14117-13135, Iran; malek@tums.ac.ir (R.M.); mpakseresht@ualberta.ca (M.P.); f.pourfarzi@arums.ac.ir (F.P.)

11 Epidemiology and Prevention Group, Center for Public Health Sciences, National Cancer Center, Tokyo 104-0045, Japan; stsugane@ncc.go.jp (S.T.); ahidaka@ncc.go.jp (A.H.)

12 Cancer Epidemiology Section, Public Health Division, Department of Health of Madrid, 28035 Madrid, Spain

13 IMIM (Hospital del Mar Medical Research Institute), 08003 Barcelona, Spain

14 Department of Public health, Universitat Pompeu Fabra (UPF), 08002 Barcelona, Spain

15 Barcelona Institute for Global Health-ISGlobal, 08036 Barcelona, Spain

16 Department of Epidemiology and Prevention, Russian N.N. Blokhin Cancer Research Center, 115478 Moscow, Russia; dgzaridze@crc.umos.ru (D.G.Z.); dmax@crc.umos.ru (D.M.)

17 Instituto de Investigación Sanitaria y Biomédica de Alicante, ISABIAL-UMH, 46020 Alicante, Spain

18 Department of Epidemiology, UCLA Fielding School of Public Health and Jonsson Comprehensive Cancer Center, Los Angeles, CA 90095-6900, USA; zfzhang@ucla.edu

19 Nikkei Disease Prevention Center, São Paulo 13010-111, Brazil; gehamada@gmx.com

20 Department of Agricultural, Food and Nutritional Sciences, University of Alberta, Edmonton, AB T6G 2R3, Canada

21 Nutritional Epidemiology Group, Centre for Epidemiology and Biostatistics, University of Leeds, Leeds LS2 9JT, UK

22 Digestive Disease Research Center, Ardabil University of Medical Sciences, Ardabil 56189-85991, Iran

23 Department of Epidemiology and Environmental Health, School of Public Health and Health Professions, University at Buffalo, Buffalo, NY 14261, USA; linamu@buffalo.edu

24 Section of Hygiene, University Department of Life Sciences and Public Health, Università Cattolica del Sacro Cuore, 20123 Rome, Italy; Stefania.Boccia@unicatt.it (S.B.); Roberta.Pastorino@unicatt.it (R.P.) 
25 Department of Woman and Child Health and Public Health—Public Health Area, Fondazione Policlinico Universitario A. Gemelli IRCCS, 00168 Roma, Italy

26 Medical Informatics Center, Peking University, Beijing 100191, China; yugp@msn.com

27 Department of Public and Community Health, School of Public Health, University of West Attica, 12243 Athens, Greece; alagiou@uniwa.gr

28 Department of Hygiene, Epidemiology and Medical Statistics, School of Medicine, National and Kapodistrian University of Athens, 15784 Athens, Greece; plagiou@hsph.harvard.edu

29 Department of Epidemiology, Harvard T.H. Chan School of Public Health, Boston, MA 01451, USA

* Correspondence: ybenavente@iconcologia.net; Tel.: +34-932607812

+ These authors contributed equally to this work.

Simple Summary: Research is still required to establish the relationship between family history (FH) and gastric cancer (GC) in relation to different histological types and anatomical sites. The present work aimed to examine the influence of first-degree FH on the risk of GC, also according to the GC location and histological type, including 5946 cases and 12,776 controls from 17 studies of 11 countries in three continents participating in the Stomach Cancer Pooling (StoP) Project consortium. This analysis confirms the effect of FH on the risk of GC, reporting an approximately doubled risk, and provides further quantification of the risk of GC according to the subsite and histotype.

Abstract: Although there is a clear relationship between family history (FH) and the risk of gastric cancer (GC), quantification is still needed in relation to different histological types and anatomical sites, and in strata of covariates. The objective was to analyze the risk of GC according to first-degree FH in a uniquely large epidemiological consortium of GC. This investigation includes 5946 cases and 12,776 controls from 17 studies of the Stomach Cancer Pooling (StoP) Project consortium. Summary odds ratios (OR) and the corresponding 95\% confidence intervals (CIs) were calculated by pooling study-specific ORs using fixed-effect model meta-analysis techniques. Stratified analyses were carried out by sex, age, tumor location and histological type, smoking habit, socioeconomic status, alcohol intake and fruit consumption. The pooled OR for GC was 1.84 (95\% CI: 1.64-2.04; I2 = 6.1\%, $\mathrm{P}$ heterogeneity $=0.383$ ) in subjects with vs. those without first-degree relatives with GC. No significant differences were observed among subgroups of sex, age, geographic area or study period. Associations tended to be stronger for non-cardia (OR $=1.82 ; 95 \% \mathrm{CI}: 1.59-2.05$ for subjects with FH) than for cardia GC (OR = 1.38; 95\% CI: 0.98-1.77), and for the intestinal (OR = 1.92; 95\% CI: 1.62-2.23) than for the diffuse histotype (OR $=1.62 ; 95 \% \mathrm{CI}$ : 1.28-1.96). This analysis confirms the effect of FH on the risk of GC, reporting an approximately doubled risk, and provides further quantification of the risk of GC according to the subsite and histotype. Considering these findings, accounting for the presence of $\mathrm{FH}$ to carry out correct prevention and diagnosis measures is of the utmost importance.

Keywords: gastric cancer; family history; international consortium; meta-analyses

\section{Introduction}

Gastric cancer (GC) is the fifth leading cause of cancer by incidence and the third leading cause of cancer death in both sexes worldwide. In 2018, there were an estimated one million new GC cases and nearly 800 thousand deaths [1].

The most accepted model of human gastric carcinogenesis is a multistage model in which both environmental and genetic factors are involved [2]. This includes family history (FH), genetic susceptibility, shared environmental or lifestyle factors and/or a combination of interactions. Between 80 and $90 \%$ of GCs are sporadic, 10 and $20 \%$ have a positive FH and only between 1 and 3\% show a clear Mendelian inheritance pattern [3]. Various studies have investigated the role of $\mathrm{FH}$ in relation to GC, often reporting relative risks around or over two for subjects with a positive FH of GC [4]. Such a strong association may be explained, besides the genetic component, by environmental exposures-including smoking habits, diet and particularly Helicobacter pylori infection-shared by family members. Still, an unexplained large variability between risk estimates has been reported according 
to geographic area, ethnic group and sex, as well as the histological type and location of GC [5]. Given the relatively small proportion of GC cases with a positive FH, only a few large studies to date have been able to examine the role of $\mathrm{FH}$ on different locations and histological types of GC, as well as in strata of covariates.

Five-year GC survival in most countries is less than 30\% [6]. Therefore, it is important to consider FH in prevention or early detection. The present work aims to examine the influence of first-degree $\mathrm{FH}$ on the risk of GC, also according to the GC location and histological type, in 17 studies from 11 countries in three continents participating in the Stomach Cancer Pooling (StoP) Project consortium.

\section{Materials and Methods}

The StoP Project is a consortium of epidemiological studies on gastric cancer. A detailed description of its aims and methods has been provided elsewhere [7]. Inclusion criteria for study participation were: case-control study design, including nested casecontrol within cohort studies, and inclusion of at least 80 cases of incident, histologically confirmed GC (including both cardia and non-cardia locations). In addition, the original questionnaires and useful information were collected to help with data handling from studies, in order to optimize data harmonization.

For this analysis, the studies were selected from the StoP consortium studies that had both the family history information and the covariates that we used in the models. This work is based on the second data release of the StoP Project, where 17 studies [8-25] conducted in 11 countries had data on the FH of GC and were examined, including a total of 5946 cases and 12,776 controls. The following data were extracted: (i) main study variables, including study design, geographic area, study period, single center/multicentric study and study center if multicentric; (ii) relevant covariates, including sex, age, education/social class, body mass index, total alcohol consumption, smoking habit, H. pylori infection and consumption of fruit and vegetables; (iii) specific cancer-related variables (for cases only), including cancer subsite and histotype; (iv) FH of GC among first-degree relatives (parents, siblings and offspring). All of the above variables were harmonized centrally according to a pre-specified format. Furthermore, any additional information related to the FH of GC available in each study (e.g., age at GC occurrence in relatives, type of relative affected) was considered.

The StoP Project received ethical approval from the University of Milan Review Board (reference 19/15 on 1 April 2015).

To estimate the association between FH and GC, a two-stage modeling approach was used [26]. First, the association in each study was assessed by calculating the odds ratio (OR) and the corresponding 95\% confidence interval (CI) using multivariate logistic regression models including terms for sex, age, socioeconomic level, smoking status and alcohol consumption. In the second stage, summary effect estimates were computed by pooling study-specific ORs using fixed-effect model meta-analysis techniques. Heterogeneity between studies was evaluated using the $\mathrm{Q}$ test statistics and quantified using $\mathrm{I}^{2}$ - that is, the proportion of total variation contributed by between-study variance [27].

To investigate whether the role of FH was heterogeneous across strata of selected covariates, analyses stratified by sex, age, socioeconomic status, GC location (cardias/non cardias), histological subtype (intestinal, diffuse), tobacco smoking, socioeconomic status, alcohol intake, fruit consumption and $H$. pylori infection were carried out. Additional analyses were carried out according to type of study, control selection system (matched or by frequency), source of controls (population or hospital) and study period (XX or XXI century).

\section{Results}

The main characteristics of the StoP Project studies included in the present analysis are shown in Table 1. Most studies were conducted in European countries (82.3\% of the controls, and $77.9 \%$ of the cases). Overall, $15.8 \%$ of cases $(n=942)$ and $7.7 \%$ of the controls 
( $n=979$ ) had an FH of stomach cancer in first-degree relatives, ranging from 4.4 to $23.0 \%$ among cases, and from 1.0 to $16.8 \%$ among controls.

Table 1. Main characteristics of the StoP Project studies included in the analyses.

\begin{tabular}{|c|c|c|c|c|c|c|c|c|}
\hline \multirow[b]{2}{*}{$\begin{array}{c}\text { StoP } \\
\text { Study ID }\end{array}$} & \multirow[b]{2}{*}{ Study Area(s) } & \multirow[b]{2}{*}{ Period } & \multirow[b]{2}{*}{ Study Type } & \multicolumn{2}{|c|}{ Cases } & \multicolumn{2}{|c|}{ Controls } & \multirow[b]{2}{*}{ References } \\
\hline & & & & $\begin{array}{c}\text { With } \\
\text { FH }\end{array}$ & Total & $\begin{array}{c}\text { With } \\
\text { FH }\end{array}$ & Total & \\
\hline 1 & Milan, Italy & 1985-1997 & CC, hospital-based & 97 & 768 & 110 & 2081 & La Vecchia et al. [8] \\
\hline 3 & Milan, Italy & 1997-2007 & CC, hospital-based & 30 & 230 & 31 & 547 & Foschi et al. [9] \\
\hline 4 & Rome, Italy & 2006-2010 & CC, hospital-based & 12 & 152 & 16 & 411 & De Feo et al. [10] \\
\hline 5 & Four areas, Italy & 1985-1987 & CC, population-based & 213 & 1016 & 138 & 1159 & Palli et al. [11] \\
\hline 6 & Athens, Greece & 1981-1984 & CC, hospital-based & 8 & 86 & 1 & 97 & Lagiou et al. [12] \\
\hline 8 & Taixing, Jiangsu, China & 2000 & CC, population-based & 31 & 206 & 14 & 415 & Mu et al. [13] \\
\hline 9 & Moscow, Russia & 1996-1997 & CC, hospital-based & 74 & 433 & 76 & 593 & Zaridze et al. [14] \\
\hline 10 & Ardabil, Iran & 2004-2005 & CC, population-based & 31 & 217 & 24 & 394 & Pourfarzi et al. [15] \\
\hline 11 & Ardabil, Iran & 2005-2007 & CC, population-based & 27 & 286 & 19 & 304 & Pakseresht et al. [16] \\
\hline 13 & Yangzhong, China & 1995 & CC, population-based & 9 & 133 & 16 & 433 & Setiawan et al. [17] \\
\hline 17 & North of Portugal & 2001-2006 & CC, population-based & 134 & 584 & 68 & 612 & Lunet et al. [25] \\
\hline 21 & Ten provinces, Spain & 2008-2013 & CC, population-based & 70 & 435 & 208 & 3418 & Castaño-Vinyals et al. [18] \\
\hline 22 & Five counties, Sweden & 1989-1995 & CC, population-based & 111 & 561 & 155 & 1164 & Ye et al. [19] \\
\hline 23 & Two provinces, Spain & 1995-1999 & CC, hospital-based & 30 & 367 & 23 & 433 & Santibañez et al. [20] \\
\hline 28 & Brazil-Brazilian origin & 1991-1994 & CC, hospital-based & 10 & 226 & 4 & 226 & Nishimoto et al. [22] \\
\hline 29 & Brazil-Japanese origin & 1991-1994 & CC, hospital-based & 17 & 93 & 25 & 186 & Hamada et al. [23] \\
\hline 30 & Japan & 1998-2002 & CC, hospital-based & 38 & 153 & 51 & 303 & Machida-Montani et al. [24] \\
\hline
\end{tabular}

Table 2 shows the frequency distribution of cases and controls according to the selected covariates. Cases were more frequently male $(63.7 \%$ vs. $58.3 \%)$, aged 65 or older $(50.5 \%$ vs. $43.0 \%)$ and of a low socioeconomic status (63.9\% vs. $52.1 \%$ ) compared to controls. Furthermore, cases were more frequently current smokers (28.9\% vs. $25.8 \%)$ and reported a high alcohol intake (14.5\% vs. $10.6 \%)$ and a low consumption of fruit (36.3\% vs. $29.0 \%)$ compared to controls.

In all studies, first-degree FH was positively related to GC, with ORs ranging between 1.46 and 11.26 (Figure 1). The differences observed were statistically significant in 10 out of the 17 studies included. The pooled OR of all studies was 1.84 (95\% CI = 1.64-2.04; $\left.\mathrm{I}^{2}=6.1 \%, \mathrm{P}_{\text {heterogeneity }}=0.383\right)$.

\section{StoP Project Estimates}

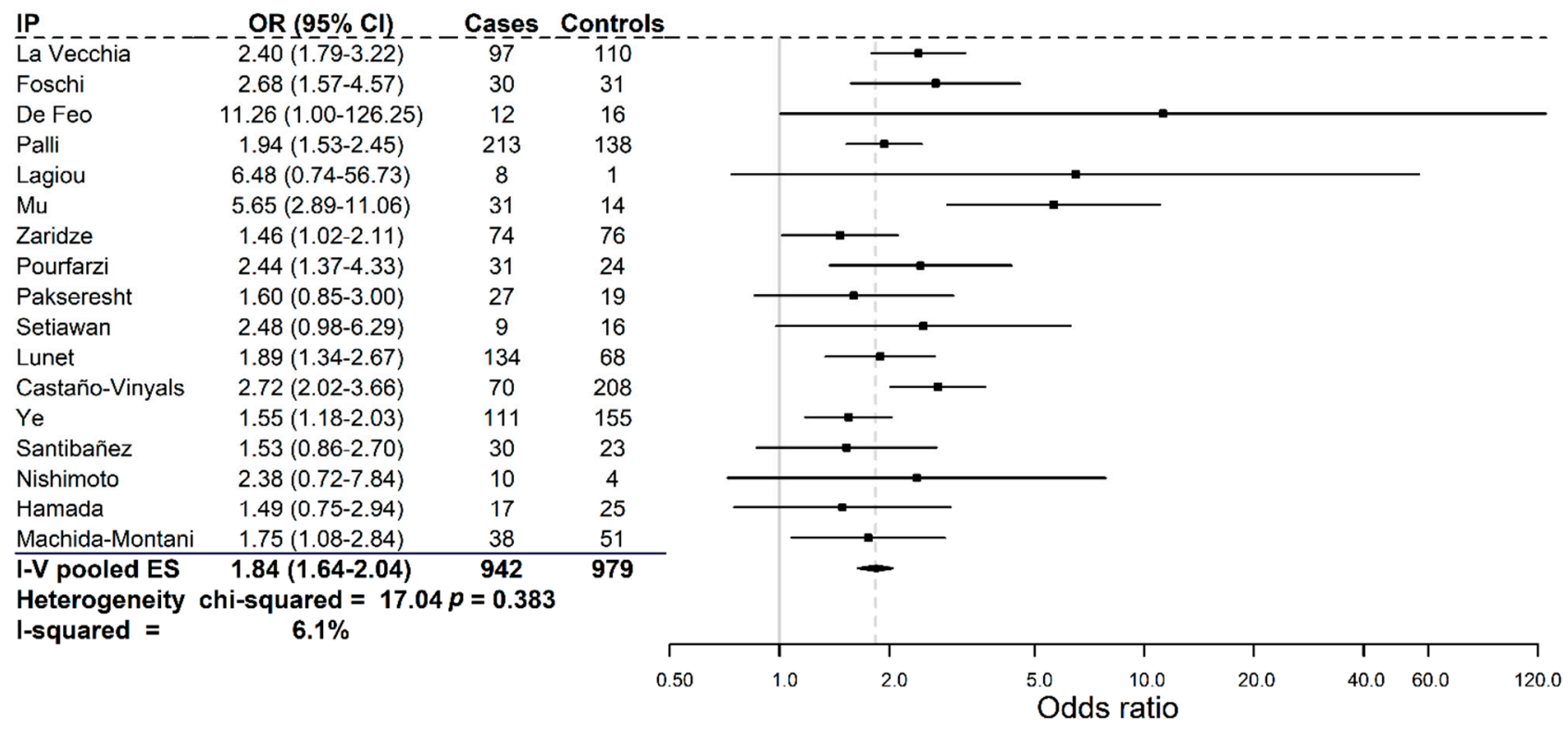

Figure 1. Pooled adjusted odds ratios with $95 \%$ confidence intervals for GC related to family history in the StoP Project. 
Table 2. Distribution of cases and controls according to selected covariates.

\begin{tabular}{|c|c|c|c|c|}
\hline \multirow{2}{*}{ Variables } & \multicolumn{2}{|c|}{ Cases } & \multicolumn{2}{|c|}{ Controls } \\
\hline & $n$ & $\%$ & $n$ & $\%$ \\
\hline \multicolumn{5}{|c|}{ Sex } \\
\hline Male & 3790 & 63.7 & 7454 & 58.3 \\
\hline Female & 2156 & 36.3 & 5322 & 41.7 \\
\hline \multicolumn{5}{|c|}{ Age } \\
\hline $18-49$ & 759 & 12.8 & 2553 & 20.0 \\
\hline $50-65$ & 2184 & 36.7 & 4724 & 37.0 \\
\hline $65-74$ & 2171 & 36.5 & 3940 & 30.8 \\
\hline $75-106$ & 832 & 14.0 & 1557 & 12.2 \\
\hline Missing & 0 & 0.0 & 2 & 0.0 \\
\hline \multicolumn{5}{|c|}{ Socioeconomic status } \\
\hline Low & 3799 & 63.9 & 6488 & 50.8 \\
\hline Medium & 1543 & 26.0 & 3760 & 29.4 \\
\hline High & 501 & 8.4 & 2198 & 17.2 \\
\hline Missing & 103 & 1.7 & 330 & 2.6 \\
\hline \multicolumn{5}{|c|}{ Smoking habit (1) } \\
\hline Current & 1720 & 28.9 & 3255 & 25.5 \\
\hline No & 4132 & 69.5 & 9386 & 73.4 \\
\hline Missing & 94 & 1.6 & 135 & 1.1 \\
\hline \multicolumn{5}{|c|}{ Alcohol intake g of ethanol/day } \\
\hline Never & 1526 & 25.7 & 3375 & 26.4 \\
\hline Low $(\leq 12)$ & 1190 & 20.0 & 3468 & 27.1 \\
\hline $\begin{array}{l}\text { Intermediate } \\
\quad(>12-47)\end{array}$ & 1745 & 29.4 & 3047 & 23.9 \\
\hline High $(>47)$ & 860 & 14.5 & 1353 & 10.6 \\
\hline Missing & 625 & 10.5 & 1533 & 12.0 \\
\hline \multicolumn{5}{|c|}{ Fruit intake (2) } \\
\hline Low & 2157 & 36.3 & 3701 & 29.0 \\
\hline Medium & 1872 & 31.5 & 4109 & 32.2 \\
\hline High & 1685 & 28.3 & 4293 & 33.6 \\
\hline Missing & 232 & 3.9 & 673 & 5.3 \\
\hline \multicolumn{5}{|c|}{ H. pylori infection } \\
\hline Positive & 688 & 11.6 & 3662 & 28.7 \\
\hline Negative & 1661 & 27.9 & 1252 & 9.8 \\
\hline Missing & 3597 & 60.5 & 7862 & 61.5 \\
\hline
\end{tabular}

(1) No: never and former; (2) defined according to study-specific tertiles.

Regarding the analysis of the type of family member affected, Figure 2 shows that the pooled OR for siblings was higher than for parents $(1.62 ; 95 \% \mathrm{CI}=1.20-2.05$, and 1.54 ; $95 \% \mathrm{CI}=1.28-1.80$, respectively). No significant heterogeneity was observed.

Figure 3 shows the results from the stratified analyses. No significant differences were found by sex,$+68 \%$ in men and $+91 \%$ in women. Thirteen and fourteen studies provided information on the location of cardia and non-cardia GC, respectively. Of the 695 cardia GC cases, $92(13.2 \%)$ had a first-degree FH of GC, while $648(17.6 \%)$ of the 3676 non-cardia GC cases had a first-degree FH of GC. The pooled ORs were $1.38(95 \% \mathrm{CI}=0.98-1.77)$ and 1.82 $(95 \% \mathrm{CI}=1.59-2.05)$, respectively. Twelve studies reported information on the histological classification of GC. Of the 2030 intestinal GC cases, 365 (18.0\%) had a first-degree FH of $\mathrm{GC}$, yielding a pooled OR of $1.92(95 \% \mathrm{CI}=1.62-2.23)$. The diffuse histological GC type was reported in 1170 cases, with $169(14.4 \%)$ having a first-degree FH of GC. The pooled OR for all studies was $1.62(95 \% \mathrm{CI}=1.28-1.96)$. There were no significant differences according to age, smoking habit, socioeconomic status, alcohol intake, fruit consumption or H. pylori infection.

Furthermore, no significant differences were observed according to whether the studies were performed in European $(\mathrm{OR}=1.84,95 \% \mathrm{CI}=1.62-2.06)$ or non-European populations $(\mathrm{OR}=1.86,95 \% \mathrm{CI}=1.33-2.38)$; were matched $(\mathrm{OR}=1.83,95 \% \mathrm{CI}=1.30-2.36)$ or not-matched $(\mathrm{OR}=1.85,95 \% \mathrm{CI}=1.63-2.07)$; and were multicentric $(\mathrm{OR}=1.83$; 
$95 \% \mathrm{CI}=1.57-2.09)$ or not $(\mathrm{OR}=1.87,95 \% \mathrm{CI}=1.54-2.21)$. Modest differences were observed according to the type of controls (hospital-based controls: OR $=1.76$, 95\% CI = 1.43-2.09; population-based controls: $\mathrm{OR}=1.90,95 \% \mathrm{CI}=1.64-2.15)$, and to the study period before the year $2000(\mathrm{OR}=1.75,95 \% \mathrm{CI}=1.51-1.98)$ or after the year 2000 $(\mathrm{OR}=2.11,95 \% \mathrm{CI}=1.72-2.50)$.

\section{StoP Project Estimates-FH Siblings}

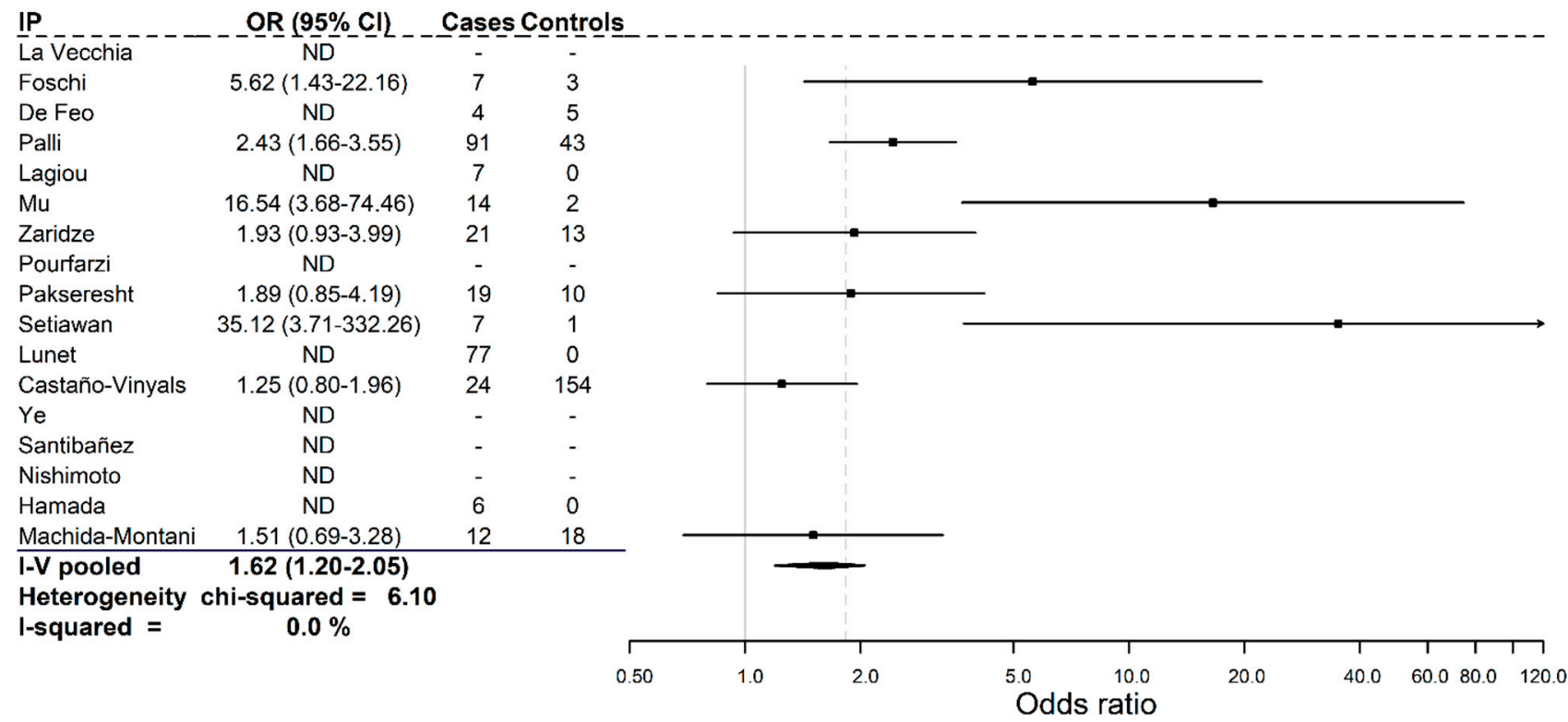

StoP Project Estimates-FH parents

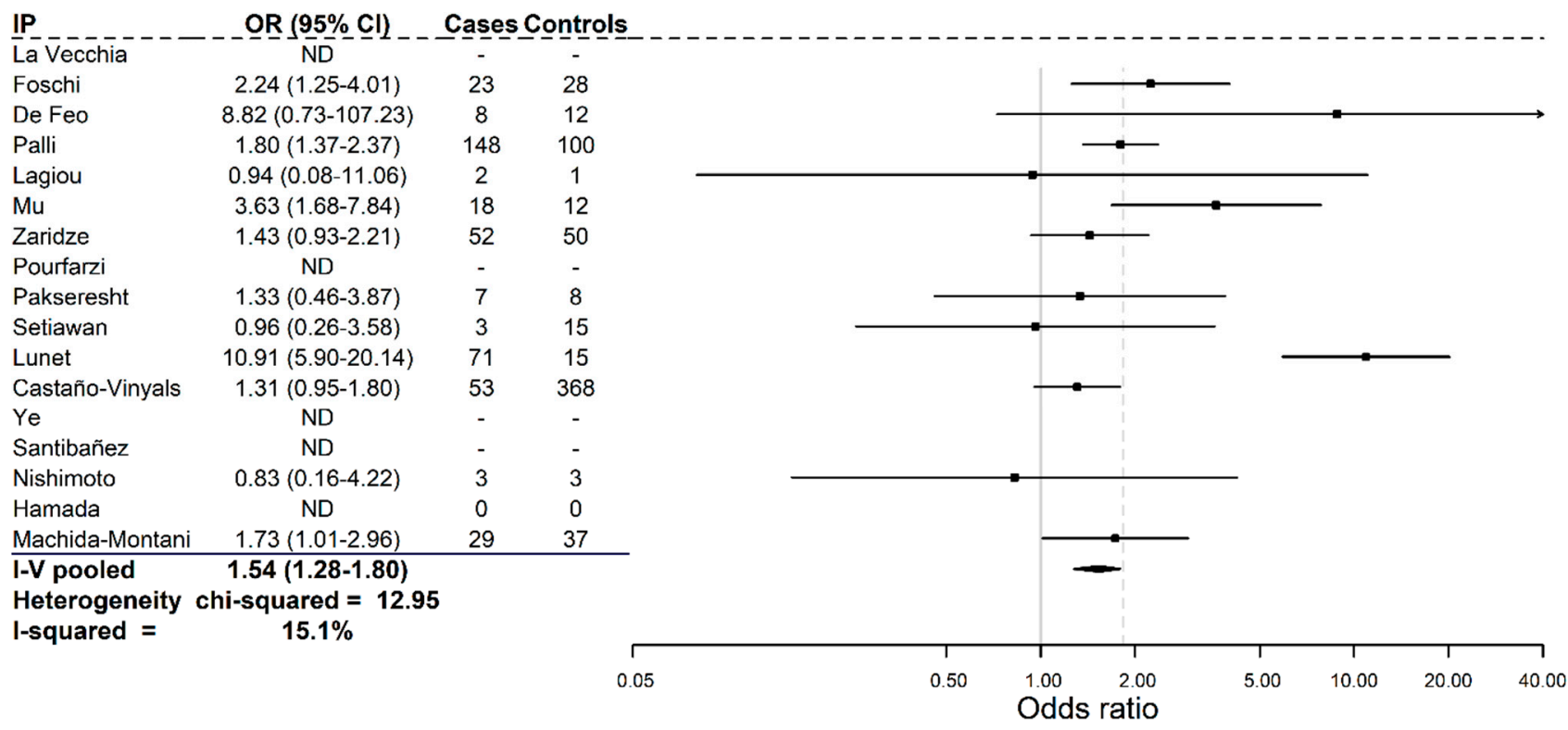

Figure 2. Pooled adjusted odds ratios with $95 \%$ confidence intervals considering the type of relative affected. 
Stratified Analyses

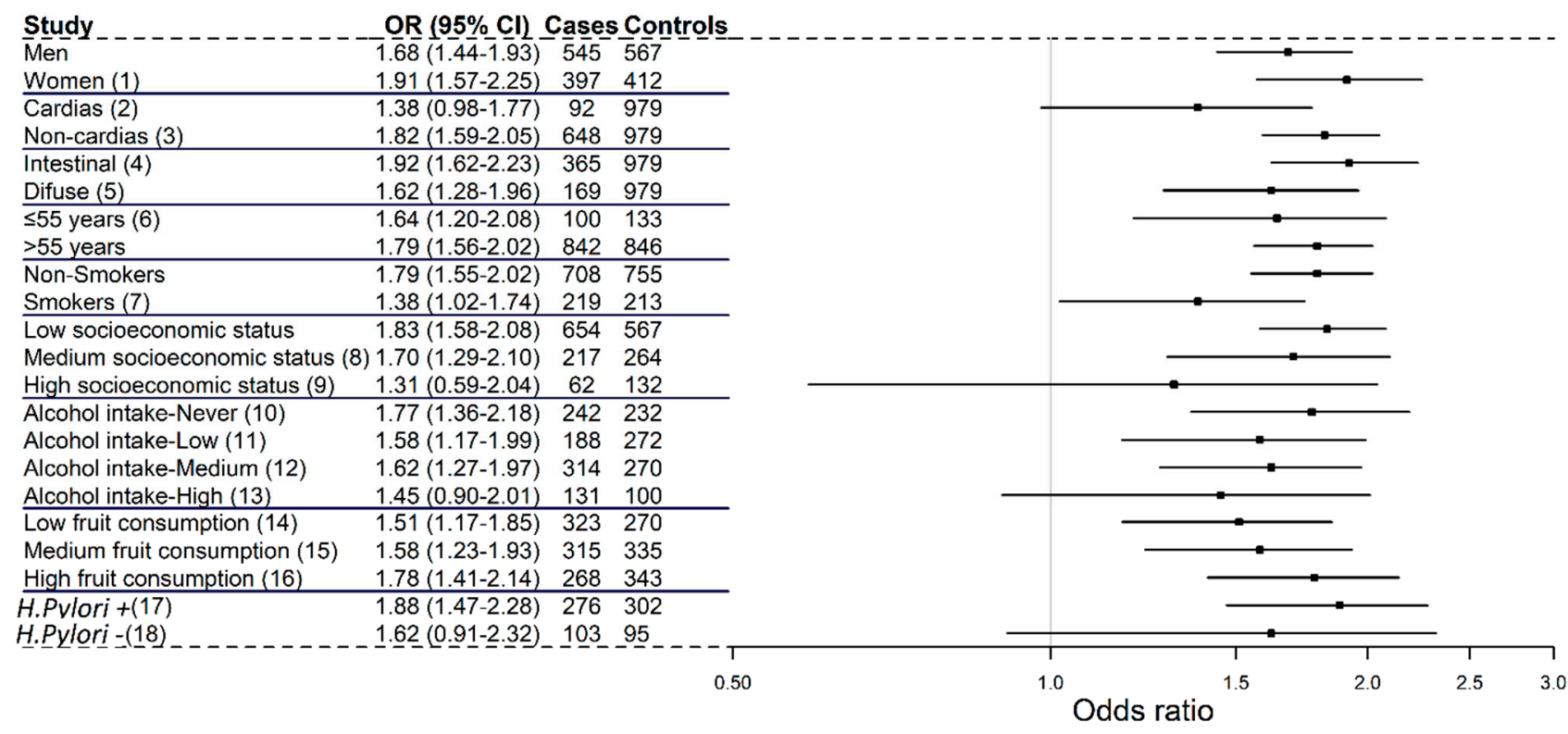

Figure 3. Pooled adjusted odds ratios with $95 \%$ confidence intervals for gastric cancer associated with a family history of gastric cancer stratified by sex, age, socioeconomic status, gastric cancer location, histological subtype, tobacco smoking, alcohol intake, fruit consumption and Helicobacter pylori infection in the StoP Project. No information for studies: (1) De Feo, Lagiou; (2) Foschi, Lagiou, Mu, Setiawan; (3) Mu, Setiawan; (4) La Vecchia, Lagiou, Mu, Setiawan, Machida-Montani; (5) La Vecchia, Lagiou, Mu, Setiawan, Machida-Montani; (6) De Feo, Lagiou, Pourfarzi, Pakseresht, Castaño-Vinyals; (7) De Feo, Lagiou, Pourfarzi, Pakseresht, Castaño-Vinyals, Nishimoto; (8) De Feo, Lagiou, Pourfarzi, Pakseresht, Castaño-Vinyals, Nishimoto; (9) De Feo, Palli, Lagiou, Pourfarzi, Setiawan, Santibañez; (10) De Feo, Lagiou, Pakseresht, Setiawan; (11) De Feo, Lagiou, Pourfarzi, Pakseresht, Setiawan, Nishimoto, Hamada; (12) Mu, Pourfarzi, Pakseresht, Setiawan, Nishimoto, Hamada; (13) De Feo, Lagiou, Mu, Pourfarzi, Pakseresht, Setiawan, Ye, Nishimoto, Hamada; (14) Lagiou, Hamada; (15) De Feo, Satiawan, Nishimoto; (16) De Feo, Lagiou, Setiawan; (17) La Vecchia, Foschi, De Feo, Palli, Lagiou, Setiawan, Santibañez; (18) La Vecchia, Foschi, De Feo, Palli, Lagiou, Pakseresht, Setiawan.

\section{Discussion}

The results of this uniquely large collaborative study confirm and quantify the influence of FH on the development of GC better than previously available studies. History of GC in a first-degree relative has been found to increase the risk of GC by about $85 \%$. In this pooled investigation, results were suggestive of a possible higher risk of non-cardia than of cardia GC in subjects with a positive FH of gastric cancer, whereas no relevant differences were observed in strata of sex, in the histological type of GC or in the characteristics analyzed in epidemiological studies.

The family aggregation of GC is due to a complex interaction between genetic inheritance and environmental and lifestyle factors [28]. It is known that between 10 and 20\% of people who develop GC have a FH, but only part of this can be attributed to hereditary syndromes. The three primary familial gastric cancers include hereditary diffuse gastric cancer [3], familial intestinal gastric cancer and gastric adenocarcinoma and proximal polyposis of the stomach, caused by germline mutations in genes such as CDH1, CTNNA1 and APC [29]. The remaining part may be due to low-penetrance genes, which, due to their interaction with the family-shared environment, have an important influence [30]. In this way, the genetic inheritance, the unique environment of each individual and the aforementioned family-shared environment can be divided into three pathways of GC development. A study conducted among twins found that these causes account for $28 \%$, $62 \%$ and $10 \%$ of the variation in GC susceptibility, respectively [31].

Our results do not show relevant differences according to sex. Though findings of different studies have varied, with some of them reporting a stronger risk related to FH 
among women [32], our finding is broadly consistent with the conclusions of several reviews $[8,11,16,20]$. Additionally, our results on the GC subsite are consistent with those from a meta-analysis, indicating that $\mathrm{FH}$ has a greater relative risk (RR) on non-cardia GC $(\mathrm{RR}=1.97 ; 95 \% \mathrm{CI}=1.72-2.25)$ than on cardia GC $(\mathrm{RR}=1.46 ; 95 \% \mathrm{CI}=0.89-2.39)$ [28] Kharazmi et al. also showed similar results in a nationwide Swedish cohort study, where the standardized incidence ratio (SIR) of cardia GC associated with a positive $\mathrm{FH}$ of cancer at the same subsite was lower $(\mathrm{SIR}=1.70 ; 95 \% \mathrm{CI}=1.10-2.50)$ compared to non-cardia subclasses-antrum $(\mathrm{SIR}=5.5 ; 95 \% \mathrm{CI}=2.4-11.00)$ and body $(\mathrm{SIR}=4.6$; $95 \% \mathrm{CI}=2.6-7.4$ ) [33]. A large percentage of non-cardia GC cases are attributed to $H$. pylori infection and, therefore, are more likely associated with family transmission [33]. On the other hand, cardia GC is more likely related to lifestyle factors, with issues such as obesity (increases the risk of cardia GC by 82\%) [34-36], gastroesophageal reflux (increases the risk two to four times) [19,37] and tobacco smoking [38].

The results of the present study show a higher risk of GC when the affected relatives were siblings rather than parents, which is in line with previous studies reporting that the association tends to be stronger among siblings than between parents and offspring $[5,28,39,40]$. However, one of the limitations of our study is that neither offspring nor the age at diagnosis of the affected family member could be included due to the small sample available for these specific analyses.

Regarding the histological type of GC, our results show that a FH of GC is associated with both intestinal and diffuse subtypes, which is consistent with findings from the prospective Alpha-Tocopherol, Beta-Carotene (ATBC) Cancer Prevention Study [28], which suggested similarly increased risks in both histological subtypes of GC (intestinal: HR 1.53, 95\% CI 0.92-2.55; diffuse: HR 1.47, 95\% CI 0.72-3.03). However, by taking advantage of the study consortium approach, our findings were based on a larger number of cases for both histotypes, and therefore our estimates are more robust.

H. pylori infection is the major environmental factor in gastric carcinogenesis. As in our study, another investigation [41] showed that patients with an FH and H. pylori infection had a slightly higher risk of GC than those without $H$. pylori infection. However, these differences were not significant.

No significant differences were found when the geographical origin of the samples of the studies included (European vs. non-European populations) was analyzed. Most previous studies on FH and GC were conducted in Asian countries, in North America and in Northern Europe [9], and this analysis has the advantage of including studies from less frequently considered areas (i.e., eight studies were from the Mediterranean region, two from Iran and two from Brazil). Furthermore, the pooled analysis patient-level approach allows for a direct comparison between estimates of different geographic areas, by limiting methodological variation (through centralized data harmonization, using the same adjustment terms in the models, etc.).

Only moderate differences were observed in relation to studies based on hospitaland population-based controls. A higher risk of GC related to FH emerged for studies conducted after the year 2000, as compared to those conducted earlier. This may be due to a decrease in the weight of environmental factors, particularly $H$. pylori infection and tobacco smoking, with respect to $\mathrm{FH}[42,43]$.

As strengths of the study, there are 5946 cases and 12,776 controls available for the analysis, accompanied by a wide variety of predictor variables, providing an adequate statistical power. Furthermore, this project is a collaborative framework, contributing with varied geographical origins. In addition, we assessed the relationship between $\mathrm{FH}$ and GC by location and histological types. The most important difference between our work and the rest of the studies and meta-analyses is that, in our case, we worked with a consortium of studies, meaning we directly used the study data instead of the ORs of the published articles. This allows us to adjust all studies for the same variables and to have more homogeneity in the results. 


\section{Conclusions}

Our results confirm and further quantify the effect of FH on the development of GC. Subjects with an FH of GC among first-degree relatives have an approximately doubled risk of GC occurrence. It is important to take into account the presence of an FH to carry out GC prevention measures, both primary and secondary, i.e., early diagnosis.

Author Contributions: Conceptualization, F.V.-S., M.R.-G., C.P. and Y.B.; methodology, M.R.-G., F.V.-S., V.M. and C.L.V.; software F.V.-S., M.R.-G. and V.M.; validation, C.P., C.L.V., R.B. and E.N.; formal analysis M.R.-G., F.V.-S. and V.M.; investigation, M.R.-G., F.V.-S., M.R., D.P., M.F., N.L., S.M. and W.Y.; data curation, M.R.-G., F.V.-S., V.M., C.P., R.B. and M.F.; writing-review and editing, A.P., R.M., S.T., A.H., N.A., G.C.-V., D.G.Z., D.M., J.V., M.G.-d.-1.-H., Z.-F.Z., G.S.H., M.P., F.P., L.M., S.B., R.P., G.-P.Y., A.L., P.L., E.N., C.L.V. and V.M. All authors have read and agreed to the published version of the manuscript.

Funding: This study was supported by the Associazione Italiana per la Ricerca sul Cancro (AIRC), Project no. 21378 (Investigator Grant). The Unidade de Investigação em Epidemiologia-Instituto de Saúde Pública da Universidade do Porto (EPIUnit) (UIDB/04750/2020) was funded by the Foundation for Science and Technology-FCT (Portuguese Ministry of Science, Technology and Higher Education). SM was also funded by the project "NEON-PC-Neuro-oncological complications of prostate cancer: longitudinal study of cognitive decline" (POCI-01-0145-FEDER-032358; ref. PTDC/SAU-EPI/32358/2017), which is funded by FEDER through the Operational Program competitiveness and Internationalization, and national funding from FCT. This work was conducted with the contribution of the Carlos III Health Institute CIBERESP CB06/02/0073, co-financed by the European Regional Development Fund ERDF, a way to build Europe. It also acknowledges the support of the Secretariat for Universities and Research of the Department of Business and Knowledge of the Generalitat de Catalunya, grants to support the activities of research groups 2017SGR01085. We thank CERCA Programme/Generalitat de Catalunya for institutional support. M.R.-G is supported by the Ministry of Education of Spain (FPU17/06488).

Institutional Review Board Statement: This study was conducted according to the guidelines of the Declaration of Helsinki and approved by the Institutional Review Board of the University of Milan (Ref 19/5-01/04/2015).

Informed Consent Statement: Informed consent was not obtained from all studies because some of them were carried out during the 1990s.

Data Availability Statement: Not applicable.

Conflicts of Interest: The authors declare no conflict of interest.

\section{References}

1. Bray, F.; Ferlay, J.; Soerjomataram, I.; Siegel, R.L.; Torre, L.A.; Jemal, A. Global Cancer Statistics 2018: GLOBOCAN Estimates of Incidence and Mortality Worldwide for 36 Cancers in 185 Countries. CA Cancer J. Clin. 2018, 68, 394-424. [CrossRef]

2. Yusefi, A.R.; Bagheri Lankarani, K.; Bastani, P.; Radinmanesh, M.; Kavosi, Z. Risk Factors for Gastric Cancer: A Systematic Review. Asian Pac. J. Cancer Prev. APJCP 2018, 19, 591-603. [CrossRef]

3. Corso, G.; Roncalli, F.; Marrelli, D.; Carneiro, F.; Roviello, F. History, Pathogenesis, and Management of Familial Gastric Cancer: Original Study of John XXIII's Family. BioMed Res. Int. 2013, 2013, 385132. [CrossRef] [PubMed]

4. Yaghoobi, M.; Bijarchi, R.; Narod, S.A. Family History and the Risk of Gastric Cancer. Br. J. Cancer 2010, 102, 237-242. [CrossRef]

5. Choi, Y.J.; Kim, N. Gastric Cancer and Family History. Korean J. Intern. Med. 2016, 31, 1042-1053. [CrossRef] [PubMed]

6. Allemani, C.; Matsuda, T.; Di Carlo, V.; Harewood, R.; Matz, M.; Niksic, M.; Bonaventure, A.; Valkov, M.; Johnson, C.J.; Esteve, J.; et al. Global Surveillance of Trends in Cancer Survival 2000-14 (CONCORD-3): Analysis of Individual Records for 37513025 Patients Diagnosed with One of 18 Cancers from 322 Population-Based Registries in 71 Countries. Lancet 2018, 39, $1023-1075$. [CrossRef]

7. Pelucchi, C.; Lunet, N.; Boccia, S.; Zhang, Z.F.; Praud, D.; Boffetta, P.; Levi, F.; Matsuo, K.; Ito, H.; Hu, J.; et al. The Stomach Cancer Pooling (StoP) Project: Study Design and Presentation. Eur. J. Cancer Prev. Off. J. Eur. Cancer Prev. Organ. 2015, 24, 16-23. [CrossRef]

8. La Vecchia, C.; D’Avanzo, B.; Negri, E.; Decarli, A.; Benichou, J. Attributable Risks for Stomach Cancer in Northern Italy. Int. J. Cancer 1995, 60, 748-752. [CrossRef]

9. Foschi, R.; Lucenteforte, E.; Bosetti, C.; Bertuccio, P.; Tavani, A.; La Vecchia, C.; Negri, E. Family History of Cancer and Stomach Cancer Risk. Int. J. Cancer 2008, 123, 1429-1432. [CrossRef] 
10. De Feo, E.; Simone, B.; Persiani, R.; Cananzi, F.; Biondi, A.; Arzani, D.; Amore, R.; D’Ugo, D.; Ricciardi, G.; Boccia, S. A Case-Control Study on the Effect of Apolipoprotein E Genotypes on Gastric Cancer Risk and Progression. BMC Cancer 2012, 12, 494. [CrossRef]

11. Palli, D.; Galli, M.; Caporaso, N.E.; Cipriani, F.; Decarli, A.; Saieva, C.; Fraumeni, J.F.; Buiatti, E. Family History and Risk of Stomach Cancer in Italy. Cancer Epidemiol. Biomark. Prev. Publ. Am. Assoc. Cancer Res. Cosponsored Am. Soc. Prev. Oncol. 1994, 3, 15-18.

12. Lagiou, P.; Samoli, E.; Lagiou, A.; Peterson, J.; Tzonou, A.; Dwyer, J.; Trichopoulos, D. Flavonoids, Vitamin C and Adenocarcinoma of the Stomach. Cancer Causes Control CCC 2004, 15, 67-72. [CrossRef] [PubMed]

13. Mu, L.N.; Lu, Q.Y.; Yu, S.Z.; Jiang, Q.W.; Cao, W.; You, N.C.; Setiawan, V.W.; Zhou, X.-F.; Ding, B.-G.; Wang, R.-H.; et al. Green Tea Drinking and Multigenetic Index on the Risk of Stomach Cancer in a Chinese Population. Int. J. Cancer 2005, 116, $972-983$. [CrossRef]

14. Zaridze, D.; Borisova, E.; Maximovitch, D.; Chkhikvadze, V. Aspirin Protects against Gastric Cancer: Results of a Case-Control Study from Moscow, Russia. Int. J. Cancer 1999, 82, 473-476. [CrossRef]

15. Pourfarzi, F.; Whelan, A.; Kaldor, J.; Malekzadeh, R. The Role of Diet and Other Environmental Factors in the Causation of Gastric Cancer in Iran-a Population Based Study. Int. J. Cancer 2009, 125, 1953-1960. [CrossRef]

16. Pakseresht, M.; Forman, D.; Malekzadeh, R.; Yazdanbod, A.; West, R.M.; Greenwood, D.C.; Crabtree, J.E.; Cade, J.E. Dietary Habits and Gastric Cancer Risk in North-West Iran. Cancer Causes Control CCC 2011, 22, 725-736. [CrossRef] [PubMed]

17. Setiawan, V.W.; Zhang, Z.F.; Yu, G.P.; Li, Y.L.; Lu, M.L.; Tsai, C.J.; Cordova, D.; Wang, M.-R.; Guo, C.H.; Yu, S.-Z.; et al. GSTT1 and GSTM1 Null Genotypes and the Risk of Gastric Cancer: A Case-Control Study in a Chinese Population. Cancer Epidemiol. Biomark. Prev. Publ. Am. Assoc. Cancer Res. Cosponsored Am. Soc. Prev. Oncol. 2000, 9, 73-80.

18. Castano-Vinyals, G.; Aragones, N.; Perez-Gomez, B.; Martin, V.; Llorca, J.; Moreno, V.; Altzibar, J.M.; Ardanaz, E.; Sanjose, S.D.; Jimenez-Moleon, J.J.; et al. Population-Based Multicase-Control Study in Common Tumors in Spain (MCC-Spain): Rationale and Study Design. Gac. Sanit. 2015, 29, 308-315. [CrossRef]

19. Ye, W.; Chow, W.H.; Lagergren, J.; Yin, L.; Nyren, O. Risk of Adenocarcinomas of the Esophagus and Gastric Cardia in Patients with Gastroesophageal Reflux Diseases and after Antireflux Surgery. Gastroenterology 2001, 121, 1286-1293. [CrossRef]

20. Santibanez, M.; Alguacil, J.; de La Hera, M.G.; Navarrete-Munoz, E.M.; Llorca, J.; Aragones, N.; Kauppinen, T.; Vioque, J. Occupational Exposures and Risk of Stomach Cancer by Histological Type. Occup. Environ. Med. 2012, 69, 268-275. [CrossRef] [PubMed]

21. Fujioka, N.; Fahey, M.T.; Hamada, G.S.; Nishimoto, I.N.; Kowalski, L.P.; Iriya, K.; Rodrigues, J.J.G.; Tajiri, H.; Tsugane, S. Serological Immunoglobulin G Antibody Titers to Helicobacter Pylori in Japanese Brazilian and Non-Japanese Brazilian Gastric Cancer Patients and Controls in Sao Paulo. Jpn. J. Cancer Res. Gann 2001, 92, 829-835. [CrossRef]

22. Nishimoto, I.N.; Hamada, G.S.; Kowalski, L.P.; Rodrigues, J.G.; Iriya, K.; Sasazuki, S.; Hanaoka, T.; Tsugane, S. São PauloJapan Cancer Project Gastric Cancer Study Group. Risk Factors for Stomach Cancer in Brazil (I): A Case-Control Study among Non-Japanese Brazilians in São Paulo. Jpn. J. Clin. Oncol. 2002, 32, 277-283. [CrossRef] [PubMed]

23. Hamada, G.S.; Kowalski, L.P.; Nishimoto, I.N.; Rodrigues, J.J.; Iriya, K.; Sasazuki, S.; Hanaoka, T.; Tsugane, S. São Paulo-Japan Cancer Project Gastric Cancer Study Group. Risk Factors for Stomach Cancer in Brazil (II): A Case-Control Study among Japanese Brazilians in São Paulo. Jpn. J. Clin. Oncol. 2002, 32, 284-290. [CrossRef] [PubMed]

24. Machida-Montani, A.; Sasazuki, S.; Inoue, M.; Natsukawa, S.; Shaura, K.; Koizumi, Y.; Kasuga, Y.; Hanaoka, T.; Tsugane, S. Association of Helicobacter Pylori Infection and Environmental Factors in Non-Cardia Gastric Cancer in Japan. Gastric Cancer Off. J. Int. Gastric Cancer Assoc. Jpn. Gastric Cancer Assoc. 2004, 7, 46-53. [CrossRef] [PubMed]

25. Lunet, N.; Valbuena, C.; Vieira, A.L.; Lopes, C.; Lopes, C.; David, L.; Carneiro, F.; Barros, H. Fruit and Vegetable Consumption and Gastric Cancer by Location and Histological Type: Case-Control and Meta-Analysis. Eur. J. Cancer Prev. 2007, 16, 312-327. [CrossRef]

26. Smith-Warner, S.A.; Spiegelman, D.; Ritz, J.; Albanes, D.; Beeson, W.L.; Bernstein, L.; Berrino, F.; Van Den Brandt, P.A.; Buring, J.E.; Cho, E.; et al. Methods for Pooling Results of Epidemiologic Studies: The Pooling Project of Prospective Studies of Diet and Cancer. Am. J. Epidemiol. 2006, 163, 1053-1064. [CrossRef]

27. Higgins, J.P.; Thompson, S.G.; Deeks, J.J.; Altman, D.G. Measuring Inconsistency in Meta-Analyses. BMJ 2003, 327, 557-560. [CrossRef]

28. Song, M.; Camargo, M.C.; Weinstein, S.J.; Best, A.F.; Mannisto, S.; Albanes, D.; Rabkin, C.S. Family History of Cancer in First-Degree Relatives and Risk of Gastric Cancer and Its Precursors in a Western Population. Gastric Cancer Off. J. Int. Gastric Cancer Assoc. Jpn. Gastric Cancer Assoc. 2018, 21, 729-737. [CrossRef] [PubMed]

29. Lott, P.C.; Carvajal-Carmona, L.G. Resolving Gastric Cancer Aetiology: An Update in Genetic Predisposition. Lancet Gastroenterol. Hepatol. 2018, 3, 874-8838. [CrossRef]

30. Butterworth, A. Family History as a Risk Factor for Common, Complex Disease; Public Health Genetics Unit PHG Found: Cambridge, UK, 2007; pp. 1-2.

31. Lichtenstein, P.; Holm, N.V.; Verkasalo, P.K.; Iliadou, A.; Kaprio, J.; Koskenvuo, M.; Pukkala, E.; Skytthe, A.; Hemminki, K. Environmental and Heritable Factors in the Causation of Cancer-Analyses of Cohorts of Twins from Sweden, Denmark, and Finland. N. Engl. J. Med. 2000, 343, 78-85. [CrossRef] 
32. Yatsuya, H.; Toyoshima, H.; Mizoue, T.; Kondo, T.; Tamakoshi, K.; Hori, Y.; Tokui, N.; Hoshiyama, Y.; Kikuchi, S.; Sakata, K.; et al. Family History and the Risk of Stomach Cancer Death in Japan: Differences by Age and Gender. Int. J. Cancer 2002, 97, 688-694. [CrossRef]

33. Kharazmi, E.; Babaei, M.; Fallah, M.; Chen, T.; Sundquist, K.; Hemminki, K. Importance of Tumor Location and Histology in Familial Risk of Upper Gastrointestinal Cancers: A Nationwide Cohort Study. Clin. Epidemiol. 2018, 10, 1169-1179. [CrossRef] [PubMed]

34. De Martel, C.; Forman, D.; Plummer, M. Gastric Cancer: Epidemiology and Risk Factors. Gastroenterol. Clin. N. Am. 2013, 42, 219-240. [CrossRef]

35. Chen, Y.; Liu, L.; Wang, X.; Wang, J.; Yan, Z.; Cheng, J.; Gong, G.; Li, G. Body Mass Index and Risk of Gastric Cancer: A Meta-Analysis of a Population with More than Ten Million from 24 Prospective Studies. Cancer Epidemiol. Biomark. Prev. Publ. Am. Assoc. Cancer Res. Cosponsored Am. Soc. Prev. Oncol. 2013, 22, 1395-1408. [CrossRef]

36. Yang, P.; Zhou, Y.; Chen, B.; Wan, H.W.; Jia, G.Q.; Bai, H.L.; Wu, X.T. Overweight, Obesity and Gastric Cancer Risk: Results from a Meta-Analysis of Cohort Studies. Eur. J. Cancer 2009, 45, 2867-2873. [CrossRef] [PubMed]

37. Figueroa, J.D.; Terry, M.B.; Gammon, M.D.; Vaughan, T.L.; Risch, H.A.; Zhang, F.F.; Kleiner, D.E.; Bennett, W.P.; Howe, C.L.; Dubrow, R.; et al. Cigarette Smoking, Body Mass Index, Gastro-Esophageal Reflux Disease, and Non-Steroidal Anti-Inflammatory Drug Use and Risk of Subtypes of Esophageal and Gastric Cancers by P53 Overexpression. Cancer Causes Control CCC 2009, 20, 361-368. [CrossRef]

38. Gonzalez, C.A.; Pera, G.; Agudo, A.; Palli, D.; Krogh, V.; Vineis, P.; Tumino, R.; Panico, S.; Berglund, G.; Siman, H.; et al. Smoking and the Risk of Gastric Cancer in the European Prospective Investigation Into Cancer and Nutrition (EPIC). Int. J. Cancer 2003, 107, 629-634. [CrossRef]

39. Bakir, T.; Can, G.; Erkul, S.; Siviloglu, C. Stomach Cancer History in the Siblings of Patients with Gastric Carcinoma. Eur. J. Cancer Prev. 2000, 9, 401-408. [CrossRef] [PubMed]

40. Bakir, T.; Can, G.; Siviloglu, C.; Erkul, S. Gastric Cancer and Other Organ Cancer History in the Parents of Patients with Gastric Cancer. Eur. J. Cancer Prev. 2003, 12, 183-189. [CrossRef] [PubMed]

41. Lee, J.; Chung, S.J.; Choi, J.M.; Han, Y.M.; Kim, J.S. Clinicopathologic Characteristics and Long-Term Outcome of Gastric Cancer Patients with Family History: Seven-Year Follow-Up Study for Korean Health Check-Up Subjects. Gastroenterol. Res. Pract. 2020, 2020, 4028136. [CrossRef] [PubMed]

42. Garcia-Esquinas, E.; Perez-Gomez, B.; Pollan, M.; Boldo, E.; Fernandez-Navarro, P.; Lope, V.; Vidal, E.; Lopez-Abente, G.; Aragones, N. Gastric Cancer Mortality Trends in Spain, 1976-2005, Differences by Autonomous Region and Sex. BMC Cancer 2009, 9, 346. [CrossRef] [PubMed]

43. Stadtlander, C.T.; Waterbor, J.W. Molecular Epidemiology, Pathogenesis and Prevention of Gastric Cancer. Carcinogenesis 1999, 20, 2195-2208. [CrossRef] [PubMed] 